\title{
Evaluation of Dental Age in Nepali Children using Demirjian's 7-Teeth Teeth Method
}

\author{
Dr Rinky Nyachhyon \\ Assoc Prof, Dept of Oral Medicine \& Radiology \\ People's Dental College, Kathmandu, Nepal
}

Correspondence: : Dr Rinky Nyachhyon; Email: kanchie78@yahoo.com

\section{ABSTRACT}

Introduction: Age estimation can be based on tooth formation stages seen on the radiographs. Demirjian's method is widely used to assess age of individuals with developing dentition. There are not many documented studies of age estimation amongst Nepali population.

Objective: To assess the applicability of Demirjian's method for dental age estimation in Nepali children.

Materials \& Method: The sample of the study consisted of 186 subjects between 7-16 years of age. Dental age estimation was based on Demirjian's method and scored by a single observer.

Result: The mean and mean differences in chronological and dental ages were calculated, which revealed the overestimation in age groups of 7 and 9 years, whereas there were underestimations in other age groups. The mean differences in age groups $12-16$ were highly significant ( $p$-Value $<0.05$ ) whereas the mean difference in age groups $7-11$ years were not statistically significant.

Conclusion: Since there is underestimation range from 0.5 years to 1.23 years, the standards of dental maturity described by Demirjian may not be suitable for Nepali children.

Keywords: age-estimation, Demirjian's method, Nepali children

\section{INTRODUCTION}

Age estimation has increasing importance not only in forensic odontology but also in dental practice. Precise evaluation of developmental stage is an integral part of both diagnosis and treatment planning in pediatric dentistry and orthodontics.' Teeth are useful tools for age estimation in children as it follows a specific timeline of dental formation, mineralization and maturation. ${ }^{2}$ In addition, mineralization of teeth is less affected by variation of nutritional and endocrine status. ${ }^{3,4}$ Estimation of dental age can be carried out, dividing it into two periods of life: first up to 20 years when the teeth are in their developing stage and later when teeth are in their regressive stage. ${ }^{5}$ Age estimation in developing stage can be performed by evaluating the rate of development, calcification of tooth buds and progressive sequence of their eruption in oral cavity. Easiest method would be the noting of eruption sequence; however it has the limitation as exact time of emergence is hard to determine, and premature loss of primary teeth influence the time of emergence of permanent teeth. ${ }^{6}$

Numerous methods have been developed for determining dental age using radiographs. Among the radiographic methods for dental age estimation in children, Demirjian's method is widely used. In 1973, Demirjian et al first used this technique in FrenchCanadian population. ${ }^{7}$ The method has been applied in various populations including Dutch, Finnish, Chinese, Belgian, Indian, Spanish, Korean, Malay, Tunisian. ${ }^{3,6,8-16}$ However, original standards elaborated for FrenchCanadian population are mostly not suitable for other populations. The aim of this study was to evaluate the accuracy of Demirjian's method in estimating the chronological age of Nepali population. 


\section{MATERIALS AND METHOD}

The sample consisted of 186 digital panoramic radiographs (OPGs) collected randomly of known age and gender from the archives of People's Dental College, Kathmandu. OPGs showing obvious dental pathology or any image deformity were excluded from the study. The study sample consisted of OPGs of 85 male and 101 female subjects of the age range $7-16$ years.

Chronological age of each patient was determined as the difference between the date of birth provided and the date on which the radiograph was taken. Dental age estimation was based on the development of seven left permanent mandibular teeth except third molar. All OPGs were examined by a single examiner. The examiner was blinded with regards to the chronological age of the patient.

Tooth formation was divided into ten stages and the criteria for stages are given for each tooth separately: Stage 0-9 ( $0=$ No crypt, $9=$ Complete root formation). Each stage was given a specific biological weighted score by Demirjian et $\mathrm{al}^{7}$ and the sum of the score provided an estimation of subject's dental maturity. The overall maturity score was then converted to dental age using the available tables. Sum of the scores gave the dental maturity which was on the scale of 0-100. These scores were converted into dental age using dental maturity curves.
Data were sub grouped by gender and age. Means and mean differences in chronological age and dental age of patients were calculated according to the age and gender. Correlation between chronological and dental age was also calculated among male and female using SPSS Version 20. Chronological age was compared with dental age using paired t-test.

\section{RESULT}

The mean difference between the chronological and dental age was statistically significant for both gender groups with the underestimation of 0.82 years in male and 1.17 years in females (Table 1). When the mean difference was calculated according to age, overestimation was seen in age group 7 and 9 by 0.80 and 0.25 years respectively. Whereas in other age groups there were underestimations ranging from 0.43 years in 11 years age group to 1.44 years in 15 years age group. The result showed that mean difference according to age was statistically significant in age groups 12-16, whereas in younger age group, the mean age difference was not statistically significant (Table 2).

Correlation between chronological and dental age was also calculated between male and female samples; the correlation coefficient were 0.867 for female and 0.719 for male which were statistically significant ( $p$-Value $<0.001)$.

Table 1: Mean difference in chronological age and dental age according to gender

\begin{tabular}{|c|c|c|c|c|c|c|c|}
\hline \multirow{2}{*}{ Gender } & \multirow{2}{*}{$\mathbf{N}$} & \multicolumn{2}{|c|}{ Chronological Age } & \multicolumn{2}{|c|}{ Dental Age } & \multirow{2}{*}{$\begin{array}{c}\text { Mean of age } \\
\text { difference }(95 \% \mathrm{Cl})\end{array}$} & \multirow{2}{*}{$p$-Value } \\
\hline & & Mean & SD & Mean & SD & & \\
\hline Male & 85 & 12.68 & 2.91 & 11.85 & 2.75 & $0.822(0.51-1.14)$ & $0.001^{*}$ \\
\hline Female & 101 & 13.75 & 2.13 & 12.59 & 2.34 & $1.17(0.84-1.50)$ & $0.001^{*}$ \\
\hline Total & 186 & 13.26 & 2.57 & 12.57 & 2.56 & $1.01(0.78-1.24)$ & $0.001^{*}$ \\
\hline
\end{tabular}

Table 2: Mean difference in chronological age and dental age according to age

\begin{tabular}{|l|c|c|c|c|c|c|c|c||}
\hline \multirow{2}{*}{ Age } & \multirow{2}{*}{$\mathbf{N}$} & \multicolumn{2}{c|}{ Chronological Age } & \multicolumn{2}{c|}{ Dental Age } & \multicolumn{2}{c|}{ Difference } \\
\cline { 3 - 9 } & & Mean & SD & Mean & SD & CA & CI & p-Value \\
\hline 7 & 10 & 7.4600 & 0.2951 & 7.5400 & 1.31335 & -0.0800 & $(-1.00-0.84)$ & 0.849 \\
\hline 8 & 6 & 8.3167 & 0.2563 & 7.8500 & 0.52058 & 0.4667 & $(-2.71-1.20)$ & 0.165 \\
\hline 9 & 13 & 9.3846 & 0.3236 & 9.6308 & 1.20027 & -0.2462 & $(-0.93-0.44)$ & 0.448 \\
\hline 10 & 6 & 10.1333 & 0.1966 & 9.3333 & 2.18510 & 0.8000 & $(-1.58-3.17)$ & 0.427 \\
\hline 11 & 12 & 11.3333 & 0.1826 & 10.9000 & 2.15870 & 0.4333 & $(-0.91-1.78)$ & 0.493 \\
\hline 12 & 16 & 12.4313 & 0.2469 & 11.6375 & 1.35296 & 0.7937 & $(0.04-1.54)$ & $0.039^{*}$ \\
\hline 13 & 31 & 13.4065 & 0.2175 & 12.1516 & 1.59580 & 1.2548 & $(0.67-1.84)$ & $0.001^{*}$ \\
\hline 14 & 24 & 14.4083 & 0.1932 & 13.0583 & 1.48585 & 1.3500 & $(0.72-1.97)$ & $0.001^{*}$ \\
\hline 15 & 53 & 15.5057 & 0.2590 & 14.0604 & 1.58834 & 1.4453 & $(1.00-1.89)$ & $0.001 *$ \\
\hline 16 & 15 & 16.0667 & 0.2320 & 14.8333 & 1.25963 & 1.2333 & $(0.56-1.90)$ & $0.002^{*}$ \\
\hline
\end{tabular}

*Statistically significant at $p<0.05$ 


\section{DISCUSSION}

Age literally means one of the periods or stages of human life. Age estimation techniques are important legally to check whether a person is minor or adult. ${ }^{17}$ Various dental age estimation methods are available; the one which uses developing teeth for age estimation provides us with two types of information: the sequence of developmental events and timing at which these events occur. Demirjian's method is one among many methods which uses developing teeth for age estimation and is widely used for its simplicity. ${ }^{18}$

Comparison of results between Nepali children and French-Canadian sample showed that the Nepali children were generally delayed in dental maturity, except for the age groups 7 and 9 where the mean difference between chronological age and dental age was found to advance. In the present study; the mean dental age difference between two populations was lesser for younger age group (7-11 years), however in older age groups, marked age differences were noticed. The marked difference in older age group can be due to pubertal growth changes. ${ }^{19}$

Demirjian's method when applied in various populations, overestimation had been noticed in most of the cases in contrast to our study. In Norwegian study, overestimation of 1.5-4 months in male and 0.35-7.5 months in females were noticed. 3 Similar observations were made in Chinese children with overestimation of 10.8 months in boys and 7.2 months in girls, ${ }^{9}$ in Northern Turkish children with overestimation of 0.36-1.43 years in male and 0.50-1.44 years in female 1 and in Malay children with overestimation of 1.23 years in male and 1.20 years in female. ${ }^{19}$ Overestimation was higher in South Indian population with 3.04 years in male and 2.82 years in female. 20 In consistent to our study, Tunisian young children of age group 3-8 years showed the underestimation of $0.26-1.37$ years. ${ }^{21}$

The present study consisted of lesser sample size. Further studies with large sample size and comparison with various ethnicities would validate the Demirjjian method in Nepali population.

\section{CONCLUSION}

The standards provided by Demirjian for French-Canadian children are not suitable for Nepali children. New formula relating to dental age needs to be developed for Nepali children. Dental age was more advanced in FrenchCanadian population compared to Nepali population.

\section{Acknowledgement}

Gratitude is expressed to Mr. Sushan Shrestha, Faculty, Institute of Medicine, TUTH for data analysis. 


\section{REFERENCES}

1. Tunc ES, Koyuturk AE. Dental age assessment using Demirjian's method on northern Turkish children. Forensic Sci Int. 2008; 175:23-6.

2. Soomer H, Ranta H, Lincoln MJ, Penttila A, Leibur E. Reliability and validity of eight dental age estimation methods for adults. J Forensic Sci. 2003; 48(1):149-52.

3. Nykanen R, Espeland L, Kvaal SI, Krogstad O. Validity of the Demirjian method for dental age estimation when applied to Norwegian children. Acta Odontol Scand. 1998; 56:238-44.

4. Foti B, Lalys L, Adalian P, Ginstiniani J, Maezel M, Signoli M, Dutour O, Leonetti G. New forensic approach to age determination in children based on tooth eruption. Forensic Sci Int. 2003; 132:49-56.

5. Solheim T, Vonen A. Dental age estimation, quality assurance and age estimation of asylum seekers in Norway. Forensic Sci Int.2006; 159:56-60.

6. Leurs IH, Wattel E, Aartman IHA, Etty E, Prahl-Andersen B. Dental age in Dutch children. Euro J Orthod. $2005 ; 27: 309-14$.

7. Demirjian A, Goldstein H, Tanner JM. A new system of dental age assessment. Hum Biol 1973; 45:21 1-7.

8. Nystrom M, Haataja J, Kataja M, Evalahti M, Peck L, Kleemola E. Dental maturity in Finnish children, estimated from the development of seven permanent mandibular teeth. Acta Odonto Scand. 1986; 44: 193-8.

9. Davis PJ, Hagg U. The accuracy and precision of "Demirijan system" when used for age determination in Chinese children. Swed Dent J. 1994; 18:113-6.

10. Williems G, Olmen AV, Splessens B, Carels C. Dental age estimation in Belgian children. Demirjian's technique revisited. J Forensic Sci. $2001 ; 46(4): 893-5$.

11. Hegde RJ, Sood PB. Dental Maturity as an indicator of chronological age: Radiographic evaluation of Dental age in 6-13 years children of Belgaum using Demirjian Methods. J Indian Soc Pedo Prev Dent. 2002; 20(4):132-8.

12. Foti B, Llys L, Adalian P, Giustiniani J, Maczel M, Signoli M, Dutour O, Leonetti G. New forensic approach to age determination in children based on tooth eruption. Forensic Sci Int. 2003; 132:49-50.

13. Rai B, Kaur J, Anand SC, Jain R, Sharma A, Mittal S. Accuracy of the Demirjian's method for the Haryana Population. Internet J Dent Sci. 2008; 6(1).

14. TeMoananui R, Kieser JA, Herbison GP, Liversidge HM. Estimating Age in Maori, Pacific Island, and European Children from New Zealand. J Forensic Sci. 2008; 53(2):401-4.

15. Lee SE, Lee SH, Lee JY, Park HK, Kim YK. Age estimation of Korean children based on dental maturity. Forensic Sci Int. 2008; 178:125-31.

16. Bijjaragi SC, Sangle VA, Saraswathi FK, Patil VS, Rani A, Bapure SK.Age estimation by modified Demirjian"s method (2004) and its applicability in Tibetian young adults: A digital panoramic study. J Oral Maxillofac Pathol. 2015; 19(1):100-5.

17. Prieto JL, Barbería E, Ortega R, Magaña C. Evaluation of chronological age based on third molar development in Spanish population. Int J Leg Med. 2005; 119:349-54.

18. Acharya AB. Age estimation in Indians using Demirjian's 8-teeth Method. J Forensic Sci. 201 1; 56(1):124-7.

19. Asab SA, Noor SNFM, Khamis MF. The accuracy of Demirjian's method in dental age estimation of Malay children. Singapore Dent J, $2011 ; 32(1): 19-27$.

20. Koshy S, Tandon S. Dental age assessment: The applicability of Demirjian's method in South Indian children. Forensic Sci Int. 1998 ; $94: 73-85$.

21. Aissaoui A, Salem NH, Maatouk F, Chadly A. Dental age assessment among Tunisian children using Demirjian method. J Forensic Dent Sci. $2016 ; 8(1): 47-51$. 